\title{
Comparing pain control using oral acetaminophen versus dorsal penile block in neonatal circumcision
}

\author{
Olakayode O. Ogundoyin ${ }^{1,2^{*}}$ D, Dare I. Olulana ${ }^{1,2}$, Taiwo A. Lawal ${ }^{1,2}$ and Felix O. Kumolalo ${ }^{2}$
}

\begin{abstract}
Background: Circumcision is one of the commonest surgical procedures performed yet the most controversial worldwide. Although various reasons have been suggested in support of circumcision, the pain and stress that accompany it on both neonates and mothers are factors against the procedure. This study compared pain control using oral acetaminophen syrup versus $1 \%$ lidocaine injection given as dorsal penile block during neonatal circumcision.

Results: There were 191 neonates in group A and 195 in group B. The mean age at circumcision was 23.71 (SD \pm 20.39) days, and mean weight was $3.33(S D \pm 0.74) \mathrm{kg}$. The mean pain scores for group A immediately and $1 \mathrm{~h}$ after circumcision were $4.26(\mathrm{SD} \pm 2.48)$ and 0.37 (SD \pm 1.35$)$, respectively. In group $B$, the mean pain scores immediately and $1 \mathrm{~h}$ after circumcision were 3.31 (SD \pm 2.59$)$ and $0.35(\mathrm{SD} \pm 1.19)$, respectively.

Conclusion: Penile block gives better pain control in comparison with oral acetaminophen syrup, but both agents are effective and can be combined to provide a long-lasting perioperative anaesthesia and analgesia for circumcision in the hospital setting.
\end{abstract}

Keywords: Acetaminophen syrup, Circumcision, Neonate, Pain, Penile block

\section{Background}

Circumcision in males is the surgical removal of the prepuce from the penis. It is one of the most common surgical procedures performed yet the most controversial in the world [1-3]. The procedure dates back to about 4000 years ago when it was being performed by the Egyptians and as a mark of covenant between God and Abraham [4-7]. Neonatal male circumcision is performed for various reasons, which range from medical, religious, cultural to social reasons. The controversies about circumcision stemmed from the various myths and facts about circumcision which include but not limited to the following: male circumcision helps to reduce the spread of human immunodeficiency virus infection, male circumcision is a religious and cultural practice that cannot be opposed, a boy should be circumcised to look like his father and circumcising newborn babies is

\footnotetext{
* Correspondence: honeydrops199@gmail.com

'Department of Surgery, College of Medicine, University of Ibadan, Ibadan, Nigeria

2Department of Surgery, University College Hospital, Ibadan, Nigeria
}

beneficial to their health in the future [8]. Whereas the health benefits of circumcision are recognized globally, religious and cultural reasons remain the most common indications for circumcision in the newborns [9]. Despite the controversies, the acceptance and practice of routine neonatal circumcision vary across the world. It is commonly performed in Africa, Asia $[10,11]$ and in the USA [12] in comparison with Australia, the UK and some other European countries [12, 13]. As a result of increasing acceptance of neonatal circumcision, a multidisciplinary task force was set up to come up with recommendations that will guide and enhance the safe practice of neonatal circumcision in the USA. This task force included the representatives of the American Academy of Paediatrics, the American Academy of Family Physicians, the American College of Obstetricians and Gynecologists and the Centers for Disease Control and Prevention. Among the recommendations is the provision of both sterile techniques and effective pain management during neonatal circumcision [14]. Thus, it is imperative to provide pain relief during neonatal 
circumcision; however, this must be provided safely to give a lasting health benefit to these newborns. Various agents have been used to provide anaesthesia for neonatal circumcision, and these include the use of local anaesthetic agents like lidnocaine injection without adrenaline, Eutectic Mixture of Local Anaesthetics (5\% EMLA cream) [15] and some other options (which are more commonly used in Nigeria and some other developing countries) like the use of oral acetaminophen syrup to provide analgesia, breast milk, oral sucrose solution and honey as pacifiers. Currently, there are no comparative studies on the efficacy of post-operative analgesia following neonatal circumcision. We, therefore, aimed at comparing the efficacy of oral acetaminophen syrup with that of $1 \%$ lidocaine (without adrenaline) injection given as dorsal penile block during neonatal circumcision.

\section{Methods}

A prospective randomized double-blind study of all healthy, full-term, male neonates coming for circumcision at the Surgical Outpatient Clinic of our hospital was conducted. Following an ethical approval, informed consent was obtained from the parents of the neonates who were allocated into two groups as follows: group A (neonates that were given $10 \mathrm{mg} / \mathrm{kg}$ of oral acetaminophen syrup) and group B (neonates that had penile block using $5 \mathrm{mg} / \mathrm{kg}$ of $1 \%$ lidocaine injection). The grouping was done by a nurse who was blinded to the study; she acted as a receptionist and gave them numbers as they arrived at the clinic for circumcision. Consequently, all patients with odd numbers were put in group A and those with even numbers were put in group B. The acetaminophen syrup was administered $30 \mathrm{~min}$ before the circumcision, and the $1 \%$ lidocaine injection for penile block was administered 5 min before the circumcision was commenced. All the neonates were circumcised in the operating theatre of our surgical outpatient clinic using the Plastibell as it was popularly preferred by the mothers of these neonates, and the procedures were performed mainly by the authors and the surgical trainees (Registrars). All these were done with strict adherence to the ethical principles of Declaration of Helsinki of 1975 as revised in year 2000 .

Excluded from the study were preterm neonates, neonates whose mother refused to consent to the study, neonates with haematological disorders and disorders of sexual differentiation and neonates with various anomalies of the penis like hypospadias, epispadias, micropenis, concealed penis, megalourethra and penile torsion.

These neonates were examined after the procedure and an assessment of their pain score was made using the Neonatal Infant Pain Scale (NIPS) by two of the authors, DIO for group A patients and FOK for group B patients, immediately after the procedure and $1 \mathrm{~h}$ later. NIPS is a subjective behavioural scale that can be used on both full-term and preterm infants. It makes use of facial expression, cry, breathing patterns, arms, legs and state of arousal of the infants for pain assessment. The minimum score is zero, and the maximum score is 7 . Pain, however, can be considered with a score of $\geq 4$. These were recorded in a pro forma. Other information recorded includes the gestational age of the patients at delivery, age, weight and the indication for circumcision. Data obtained were analysed using the Statistical Package for Social Sciences Version 21.0 Software (SPSS Inc., Chicago, IL, USA); the level of significance was set at $P<0.05$.

\section{Results}

A total of 385 full-term neonates were recruited into the study with 191 (49.5\%) neonates in group A and 195 $(50.5 \%)$ in group B. The mean age and weight of the neonates were $23.71(\mathrm{SD} \pm 20.39)$ days and $3.33(\mathrm{SD} \pm 0.74)$ $\mathrm{kg}$, respectively.

The mean pain score for both groups immediately after circumcision was 3.79 ( $\mathrm{SD} \pm 2.58$ ) while the mean pain score for both groups $1 \mathrm{~h}$ after the procedure was 0.36 (SD \pm 1.27 ), $p<0.001$.

The mean pain scores immediately after the procedure were $4.26(\mathrm{SD} \pm 2.48)$ in group A compared to 3.31 $(\mathrm{SD} \pm 2.59)$ in group $\mathrm{B}$ patients, $p<0.001$. The mean pain scores $1 \mathrm{~h}$ after the procedures were similar in both groups, $0.37(\mathrm{SD} \pm 1.35)$ in group A vs. $0.35(\mathrm{SD} \pm 1.19)$ in group $\mathrm{B}, p=0.878$ (Table 1 ).

In group $\mathrm{A}$, the age at circumcision was not significantly related to the mean pain score $\left(\chi^{2}=314.08, p=\right.$ $0.928)$ immediately after circumcision, but there was a significant relationship $\left(\chi^{2}=410.23, p=0.000\right) 1 \mathrm{~h}$ after, whereas there were no significant relationships between the patients' weight and the pain scores both immediately $\left(\chi^{2}=320.38, p=0.515\right)$ and $1 \mathrm{~h}\left(\chi^{2}=256.69, p=\right.$ 0.792 ) after circumcision. Similarly, there was no significant relationship between the patient's age and the pain scores immediately $\left(\chi^{2}=337.70, p=0.699\right)$ after circumcision, but there was a significant relationship 1 $\mathrm{h}\left(\chi^{2}=486.96, p=0.000\right)$ after the procedure in group B neonates; also, there were no significant relationships between the weight and the pain scores immediately $\left(\chi^{2}=380.34, p=0.937\right)$ and $1 \mathrm{~h}\left(\chi^{2}=442.22, p=0.006\right)$ after the circumcision.

Table 1 The mean pain scores for both groups

\begin{tabular}{lcl}
\hline Group & \multicolumn{2}{l}{ Mean pain scores } \\
\cline { 2 - 3 } & Immediate post op & $1 \mathrm{~h}$ post op \\
\hline A (Oral acetaminophen) & $4.26(\mathrm{SD} \pm 2.48)$ & $0.37(\mathrm{SD} \pm 1.35)$ \\
B (Penile block) & $3.31(\mathrm{SD} \pm 2.59)$ & $0.35(\mathrm{SD} \pm 1.19)$ \\
\hline
\end{tabular}




\section{Discussion}

The practice of circumcision throughout the world is controversial, and its acceptability has often been supported by its proponents with various reasons, which included medical, cultural, cosmesis, religious, and social [16]. Perhaps, all these reasons might have been given to support circumcision in the older child and adult as it is assumed that during circumcision, they will be given one form of anaesthesia or the other like any other procedures. In Nigeria and some other parts of sub-Saharan Africa, neonatal circumcisions are performed mostly outside the hospital setting and are mostly performed traditionally by local leaders, by the nurses, traditional birth attendants and nurse auxiliaries. These people are not likely to believe that neonates feel pain unlike older children and adults, they may not know how to give the anaesthesia, they may believe that the duration of the procedure is too short to administer any anaesthetic and they may also think that the cost of giving the anaesthesia if added to the total cost of the procedure may be too expensive for the parents to afford. The setting of this study was a teaching hospital where surgical trainees are exposed to the various methods of circumcision with both anaesthesia and analgesia. Circumcision is always performed by the doctors, and this helps to reduce the incidence of post-circumcision complications similar to the ones referred to our centre from the peripheral hospitals.

In a survey of parents of all male infants younger than 6 months of age attending a family practice clinic and who were asked to give reasons for accepting or refusing circumcision, $36 \%$ of the parents said that the procedure is painful for the baby [17]. Thus, providing adequate anaesthesia during and after circumcision is essential to enhancing the acceptability of the procedure and reducing the controversies surrounding it. In the hospital setting, various anaesthetic agents have been given using different methods which include topical anaesthetic cream, local anaesthesia and dorsal penile block, and their efficacies have been proven [15, 18]. This study made use of the neonatal infant pain scale to compare the mean pain scores in group A neonates who were administered $10 \mathrm{mg} / \mathrm{kg}$ of oral acetaminophen syrup 30 min before the circumcision and group $\mathrm{B}$ neonates who had dorsal penile block using $5 \mathrm{mg} / \mathrm{kg}$ of $1 \%$ lidocaine injection at the commencement of the procedure. The mean pain score was significantly much lower in group $B$ patients immediately after the procedure whereas the mean pain score was much lower in group A patients 1 $\mathrm{h}$ after the procedure, although the latter was not statistically significant. Thus, pain control was much better in group B neonates whereas neonates in group A experienced much pain immediately after the circumcision. These observations disagree with a previous study from
Turkey where there was no significant difference in the mean pain scores after $1 \mathrm{~h}$, although an intravenous acetaminophen injection was used and the cohort of patients studied was from 1 to 7 years [19]. The findings in this study may be related to the onset of action and duration of action as well as the route of administration of these agents. However, when the route of administration is almost similar as reported by Masciello [18] in which he compared local anaesthesia with dorsal penile block, local anaesthesia was reported to have demonstrated greater efficacy than the penile block and it is also easier to administer to the neonates. The non-availability of $5 \%$ EMLA Cream in our centre could not allow us to include the local route of administration for a more robust comparison in this study. There may, however, be a need for another study that would involve administration of the acetaminophen earlier than done in the present study and thus allow the acetaminophen to have reached appreciable systemic concentration before the procedure while also making use of a local anaesthetic agent.

In both groups, the age of the neonates related significantly with the mean pain score $1 \mathrm{~h}$ after circumcision whereas the weight does not have any significant relationship with the mean pain score post-operatively in both groups. However, the pain scores may be affected by the issue of painful memories at the neonatal level and inter-observer variability which was reduced to the barest minimum by using only two people to assess the pain scores.

NIPS was used to evaluate the neonates by more than one investigator. This might have increased the subjectivity of this study. However, the degree of subjectivity can be reduced in further studies by ensuring that a single investigator performs the pain assessment for both groups and is blinded to the type of analgesia administered to the infants.

Adequate management of procedural pain in neonates is essential to preventing adverse neurodevelopmental outcomes in them. Therefore, neonatal circumcision pain management must focus on prevention of pain, routine pain assessments and the use of both nonpharmacologic and pharmacologic approaches [20-23]. Neonatal pain prevention is the best way to avoid pain, and in preventing pain before the procedure, pharmacologic agents like sedatives, local anaesthetics like EMLA cream and lidocaine injection, opioids (which gives both analgesic and sedative effects), acetaminophen and nonsteroidal anti-inflammatory drugs can be used depending on the severity of the pain [21]. During the procedure, non-pharmacologic strategies can be used to augment the pain prevention. These include Kangaroo care and facilitated tucking as well as the use of breastfeeding, non-nutritive sucking, sucrose and sweeteners [20]. After the procedure, pain assessment is performed using any 
of the various neonatal pain assessment scales available depending on the degree of familiarity of the healthcare provider to these scales [22]. Pain assessment is then followed by further use of pharmacologic agents to treat any form of breakthrough pain.

This step-wise approach to pain management in neonates suggests that a multimodal approach must be employed following circumcision in this environment. Therefore, any of the following approaches can be used for effective prevention of pain associated with neonatal circumcision: the use of $1 \%$ lidocaine injection for subcutaneous ring block or dorsal penile nerve block and application of EMLA cream. This can be combined with breastfeeding, oral sucrose with or without non-nutritive sucking to provide additional pain relief during the procedure and the use of oral acetaminophen up to $48 \mathrm{~h}$ after the procedure [23].

\section{Conclusion}

In the hospital setting, the penile block is superior to oral acetaminophen in providing adequate analgesia; however, both agents are effective and can be combined together to provide a long-lasting anaesthesia and analgesia that will help to reduce the post-operative pain and stress on the neonates and their mothers respectively to the barest minimum and, therefore, improve the acceptability of the procedure. Also, the use of oral acetaminophen syrup which is a drug that is very available and cheap in many countries in sub-Saharan Africa can be recommended to other people involved in circumcision and who do not have the requisite knowledge of anaesthesia for circumcision outside the hospital setting to provide the needed analgesia for the neonates.

\section{Abbreviations}

DIO: Initials of second author; EMLA: Eutectic Mixture of Local Anaesthesia; FOK: Initials of fourth author; NIPS: Neonatal Infant Pain Scale; OOO: Initials of the first author; SD: Standard deviation; TAL: Initials of third author

\section{Acknowledgements}

Not applicable.

\section{Authors' contributions}

OOO was involved in the conception and design of the study, acquisition of data, analysis and interpretation of data, drafting the article, revising it critically for important intellectual content and final approval of the version to be submitted. DIO was involved in the conception and design of the study, acquisition of data, analysis and interpretation of data, drafting the article, revising it critically for important intellectual content and final approval of the version to be submitted. TAL was involved in the acquisition of data, analysis and interpretation of data, revising it critically for important intellectual content and final approval of the version to be submitted. FOK was involved in the acquisition of data, analysis and interpretation of data, revising it critically for important intellectual content and final approval of the version to be submitted.

\section{Funding}

We declare that this study was solely funded by the authors.

\section{Availability of data and materials}

We declare that the data sets and material used for this study are available from the corresponding author on reasonable request.

\section{Ethics approval and consent to participate}

We declare that ethical approval was obtained from our Institution's Ethics Review Committee and written informed consent (UI/EC/13/0003) was obtained from the parents of the patients before they were recruited into the study.

\section{Consent for publication}

We declare that consent for publication of this study was obtained from the parents of the patients at the time of recruitment into the study.

\section{Competing interests}

The authors declare that they have no competing interests.

Received: 3 October 2019 Accepted: 23 October 2019

Published online: 20 November 2019

\section{References}

1. Alanis MC, Lucidi RS. Neonatal circumcision: a review of the world's oldest and most controversial operation. Obstet Gynaecol Survey. 2004;59:379-95.

2. Nagdeve NG, Nalk H, Bhingare PD, Morey SM. Parental evaluation of postoperative outcome of circumcision with Plastibell or conventional dissection by dorsal slit technique: a randomized controlled trial. J Pediatr Urol. 2013;9(5):675-82.

3. Kelly BD, Lundon DJ, Timlin ME, Sheikh M, Nusrat NB, D'Arcy FT, Jaffry SQ. Paediatric sutureless circumcision - an alternative to the standard technique. Pediatr Surg Int. 2012;28:305-8.

4. Sardi L, Livingston K. Parental decision making in male circumcision. Am J Matern Child Nurs. 2015;40(2):110-5.

5. Pinto K. Circumcision controversies. Pediatr Clin N Am. 2012;59(4):977-86.

6. Henerey A. Evolution of male circumcision as normative control. J Mens Stud. 2004;12(3):265-76.

7. UNAIDS, WHO. Neonatal and child male circumcision: a global review 2015; 1-108. from http://www.who.int/hiv/pub/malecircumcision/ neonatalchildMCUNAIDS.pdf. Accessed on 2 Sept 2017

8. Intact America. The facts behind circumcision. 2017. from http://www. intactamerica.org/learnmore. Accessed on 2 Sept 2017

9. Freeman JJ, Spencer AU, Drongowski RA, Vandeven CJM, Apgar B, Teitelbaum DH. Newborn circumcision outcomes: are parents satisfied with the results? Pediatr Surg Int. 2014;30:333-8.

10. Ademuyiwa AO, Bode CO. Complications of neonatal circumcision: avoiding common pitfalls in a common procedure. Afr J Paediatr Surg. 2009;6:134-6.

11. Abdur-Rahman LO, Musa Ol, Oshagbemi GK. Community-based study of circumcision practices in Nigeria. Ann Trop Med Public Health. 2012;5:231-5.

12. Bhattacharjee PK. Male circumcision: an overview. Afr J Paediatr Surg. 2008;5:32-6.

13. Senel FM, Demirelli M, Oztek S. Minimally invasive circumcision with a novel plastic clamp technique: a review of 7,500 cases. Pediatr Surg Int. 2010:26:739-45.

14. AAP. Male circumcision. Technical Report. Paediatrics. 2012:e756-85 from www.pediatrics.org/cgi/doi/10.1542/peds.2012-1990. Accessed on Sept 2, 2017.

15. WHO, Jhipiego. Manual for early infant male circumcision under local anaesthesia; 2012. p. 1-132. from www.malecircumcision.org. Accessed on 2 Sept 2017.

16. Crawford DA. Circumcision: a consideration of some of the controversy. J Child Health Care. 2002;6:259-70.

17. Tiemstra JD. Factors affecting the circumcision decision. J Am Board Fam Pract. 1999;12:16-20.

18. Masciello AL. Anesthesia for neonatal circumcision: local anesthesia is better than dorsal penile nerve block. Obstet Gynecol. 1990;75(5):834-8.

19. Haliloglu AH, Gokce MI, Tangal S, Boga MS, Tapar H, Aladag E. Comparison of post-operative analgesic efficacy of penile block, caudal block and intravenous paracetamol for circumcision: a prospective randomized study. Int Braz J Urol. 2013:39(4):551-7.

20. Walter-Nicolet E, Annequin D, Biran V, Mitanchez D, Tourniaire B. Pain management in newborns: from prevention to treatment. Pediatr Drugs. 2010;12(6):353-65 
21. Hall RW, Anand KJS. Pain management in newborns. Clin Perinatol. 2014; 41(4):895-924. https://doi.org/10.1016/j.clp.2014.08.010.

22. Bhalla T, Shepherd E, Tobias JD. Neonatal pain management. Saudi J Anaesth. 2014;8(Suppl 1):S89-97. https://doi.org/10.4103/1658-35X.144085.

23. Ottawa Neonatal Pain Interest Group. Newborn pain management: a practical approach self-learning module: Champlain Maternal Newborn Regional Program; 2015. p. 1-22. from http://www.cmnrp.ca/uploads/documents// Newborn_Pain_SLM_2015_02_19_FINAL.pdf. Accessed on 17 June 2016.

\section{Publisher's Note}

Springer Nature remains neutral with regard to jurisdictional claims in published maps and institutional affiliations.

\section{Submit your manuscript to a SpringerOpen ${ }^{\circ}$ journal and benefit from:}

- Convenient online submission

- Rigorous peer review

- Open access: articles freely available online

- High visibility within the field

- Retaining the copyright to your article

Submit your next manuscript at $\boldsymbol{\sim}$ springeropen.com 